\title{
Article \\ Investigation of Electro-Elastic Properties for LN Single Crystals at Low Temperature
}

\author{
Feifei Chen, Chao Jiang, Fapeng Yu* ${ }^{\mathbb{D}}$, Xiufeng Cheng and Xian Zhao* \\ Center for Optics Research and Engineering, State Key Laboratory of Crystal Materials, Shandong University, \\ Jinan 250100, China; chenfeifei@sdu.edu.cn (F.C.); yjr625682805@163.com (C.J.); xfcheng@sdu.edu.cn (X.C.) \\ * Correspondence: fapengyu@sdu.edu.cn (F.Y.); zhaoxian@sdu.edu.cn (X.Z.)
}

Citation: Chen, F.; Jiang, C.; Yu, F.; Cheng, X.; Zhao, X. Investigation of Electro-Elastic Properties for LN Single Crystals at Low Temperature. Appl. Sci. 2021, 11, 7374. https:// doi.org/10.3390/app11167374

Academic Editor: John D. Clayton

Received: 14 July 2021

Accepted: 8 August 2021

Published: 11 August 2021

Publisher's Note: MDPI stays neutral with regard to jurisdictional claims in published maps and institutional affiliations.

Copyright: (c) 2021 by the authors. Licensee MDPI, Basel, Switzerland. This article is an open access article distributed under the terms and conditions of the Creative Commons Attribution (CC BY) license (https:// creativecommons.org/licenses/by/ $4.0 /)$.

\begin{abstract}
Lithium niobate crystals $\left(\mathrm{LiNbO}_{3}, \mathrm{LN}\right)$ are multifunctional crystal materials with many outstanding properties. In this work, the electro-elastic properties of LN single crystals were explored at temperatures from $-150{ }^{\circ} \mathrm{C}$ to $150{ }^{\circ} \mathrm{C}$. The temperature dependences of dielectric permittivities, elastic compliances, electromechanical coupling factors and piezoelectric coefficients were determined using the impedance method. The LN crystals possessed large dielectric permittivities, the $\varepsilon_{11}^{T} / \varepsilon_{0}$ and $\varepsilon_{33}^{T} / \varepsilon_{0}$ were 83.2 and 29.4 at room temperature, respectively. The elastic compliances $s_{11}, s_{13}, s_{33}$ and $s_{44}$ presented a positive increase as the temperature increased, and the variations were $5.0 \%$, $8.2 \%, 4.6 \%$ and $5.4 \%$, respectively, showing a good temperature stability. Moreover, the temperature dependence of the electromechanical coupling factors and piezoelectric coefficients for different vibration modes were studied with a temperature range from $-150{ }^{\circ} \mathrm{C}$ to $150{ }^{\circ} \mathrm{C}$, where the thickness shear vibration mode $d_{15}$ presented a large piezoelectric response and minimal temperature variation.
\end{abstract}

Keywords: LN crystals; electro-elastic properties; temperature stability

\section{Introduction}

Lithium niobate crystals $\left(\mathrm{LiNbO}_{3}, \mathrm{LN}\right)$ are a type of famous multifunctional materials which have excellent piezoelectric, nonlinear, photorefractive, electro-optical, acousto-optic and pyroelectric properties [1-8]. Based on these properties, LN crystals are widely used in acoustic wave transducers, acoustic filters, acoustic delay lines, electro-optical Q-switches, optical amplitude modulators and so on [9-14].

It is reported that LN crystals have large piezoelectric coefficients, measuring 6-70 pC/N [15,16]. Particular, LN crystals possess high electromechanical coupling factors. The thickness shear electromechanical coupling factor for X-cut crystals reaches $68 \%$, while the electromechanical coupling factor of quartz crystals is just $0.98 \%$ with the same condition $[17,18]$. LN crystals with outstanding piezoelectric properties are widely used in transducer applications, such as in the nondestructive testing of single crystal transducers. The piezoelectric coefficients, electromechanical coupling factors, mechanical quality factors and the Curie temperature are the main performance parameters needed to measure the performance of the single crystal transducers, which have an effect on sensitivity, efficiency, timing and temperature stability, etc. Therefore, studying the electroelastic properties of LN crystals systematically is a great supplement for the piezoelectric materials of transducers.

In previous studies, much research about the electro-elastic properties for LN crystals has been done, including the electromechanical coupling factors with different orientations, and temperature dependence in different temperature ranges, etc., $[19,20]$ while studies regarding the electro-elastic properties at low temperatures are rare. In 2012, Ryuichi Tarumi reported the elastic constants and piezoelectric coefficients, using resonant ultrasound spectroscopy from an ambient temperature to $6 \mathrm{~K}$, and discussed the elastic and piezoelectric properties from the viewpoint of group theory and lattice dynamics [21]. 
In this study, to conduct a complete investigation of the electro-elastic properties of LN crystals and be able to extensively use LN crystals in a wider temperature range, the electro-elastic properties, including the dielectric permittivities, elastic compliances, electromechanical coupling factors and piezoelectric coefficients, were measured and determined by using the impedance method from $-150{ }^{\circ} \mathrm{C}$ to $150^{\circ} \mathrm{C}$.

\section{Experimental Section}

Restricted by the crystal symmetry, the LN crystals had 3-m symmetry and possessed 2 dielectric permittivities, 6 elastic compliances and 4 piezoelectric coefficients, which are given as below:

$$
\begin{gathered}
\varepsilon_{\mathrm{ij}}=\left(\begin{array}{cccc}
\varepsilon_{11} & 0 & 0 \\
0 & \varepsilon_{11} & 0 \\
0 & 0 & \varepsilon_{33}
\end{array}\right) \\
s_{i j}=\left(\begin{array}{cccccc}
s_{11} & s_{12} & s_{13} & s_{14} & 0 & 0 \\
s_{12} & s_{11} & s_{13} & -s_{14} & 0 & 0 \\
s_{13} & s_{13} & s_{33} & 0 & 0 & 0 \\
s_{14} & -s_{14} & 0 & s_{44} & 0 & 0 \\
0 & 0 & 0 & 0 & s_{44} & 2 s_{14} \\
0 & 0 & 0 & 0 & 2 s_{14} & 2\left(s_{11}-s_{12}\right)
\end{array}\right) \\
d_{i j}=\left(\begin{array}{cccccc}
0 & 0 & 0 & 0 & d_{15} & -2 d_{22} \\
-d_{22} & d_{22} & 0 & d_{15} & 0 & 0 \\
d_{31} & d_{31} & d_{33} & 0 & 0 & 0
\end{array}\right)
\end{gathered}
$$

In this work, the cut samples were prepared from the high-quality LN single crystals, which were supplied by CETC Deqing Huaying Electronics Co., Ltd., Zhejiang, China. The crystal cut configuration was prepared based on our previous work described in [22], as showed in Figure 1. The precise orientations were carried out by $\mathrm{X}$-ray diffraction crystal direction finder ( $\mathrm{YX}-4$ made by Liaodong Radioactive Instrument Company, Dandong, China), with the accuracy of $<20^{\prime \prime}$. In this experiment, all the samples were nearly the same dimensions with the same vibration mode. The dimensions of the prepared crystal cuts were $10 \times 10 \times 2 \mathrm{~mm}^{3}$ for square plates (samples (a) and (b)), $4 \times 4 \times 12 \mathrm{~mm}^{3}$ for Z bar (samples (c)), and $1.5 \times 4 \times 15 \mathrm{~mm}^{3}$ for rectangular-shaped plates (samples (d) and (i)).

The crystal samples were vacuum-sputtered with platinum films $(200 \mathrm{~nm})$ as electrodes on the two parallel surfaces. The measurement of electro-elastic properties was carried out by the impedance method. The dielectric permittivities $\varepsilon_{11}^{T} / \varepsilon_{0}$ and $\varepsilon_{33}^{T} / \varepsilon_{0}$ were obtained by recording the capacitance of the $\mathrm{X}$ - and $\mathrm{Z}$ square plates using a multi-frequency LCR meter at $1 \mathrm{kHz}$. The resonant and anti-resonant frequencies were measured by an impedance analyzer connected to a temperature chamber. Based on the measured capacitances, resonant frequencies and anti-resonant frequencies of different crystal cuts and the electro-elastic constants were obtained. Moreover, the variations of electro-elastic characteristics were determined by Equation (4) with the temperature range from $-150{ }^{\circ} \mathrm{C}$ to $150{ }^{\circ} \mathrm{C}$ :

$$
\text { Variation }_{X}=\frac{X(T)-X\left(T_{0}\right)}{X\left(T_{0}\right)}
$$

where $X(T)$ represents the dielectric permittivity, elastic compliance, electromechanical coupling factor and piezoelectric coefficient at arbitrary temperature; $X\left(T_{0}\right)$ represents these parameters at $-150^{\circ} \mathrm{C}$. 


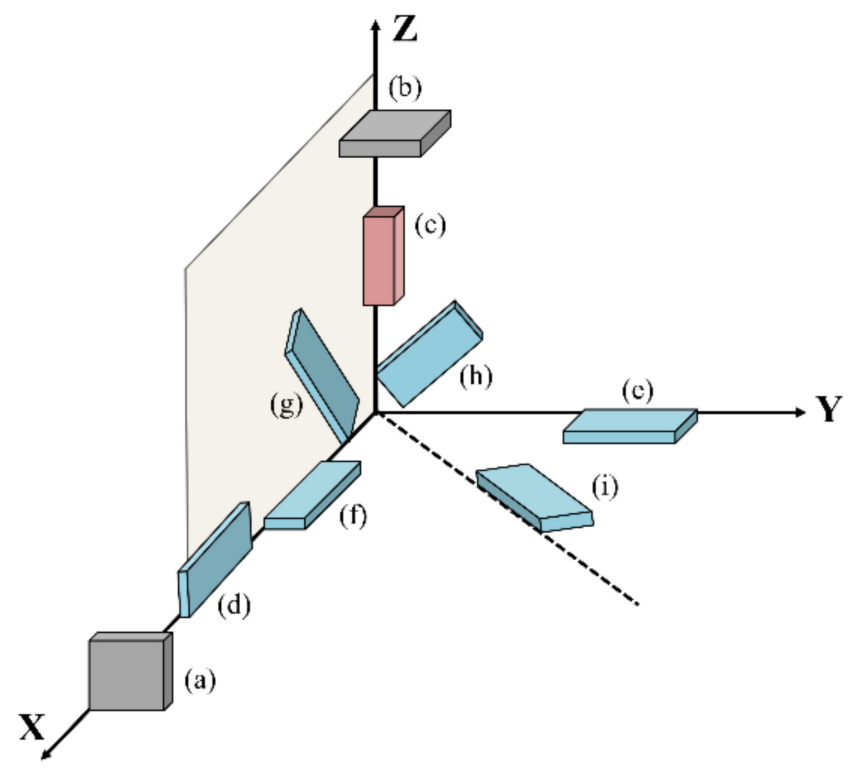

Figure 1. Schematic configuration for the evaluation of electro-elastic constants: (a) $X$-square plate; (b) Z-square plate; (c) Z bar; (d) YX plate; (e) ZY plate; (f) ZX plate; (g) YZt $/ \theta\left(\theta=30^{\circ}, 45^{\circ}\right.$ and $\left.60^{\circ}\right)$; (h) $\mathrm{XYt} / \theta\left(\theta=60^{\circ}\right)$; and (i) $\mathrm{ZXt} / \theta\left(\theta=70^{\circ}\right.$ and $\left.80^{\circ}\right)$.

\section{Results and Discussion}

\subsection{Temperature Dependence of Dielectric Permittivity}

The variation of relative dielectric permittivities $\left(\Delta \varepsilon_{\mathrm{ii}}^{T} / \varepsilon_{0}\right) /\left(\varepsilon_{\mathrm{ii}}^{T_{0}} / \varepsilon_{0}\right)\left(\Delta \varepsilon_{\mathrm{ii}}^{T} / \varepsilon_{0}=\varepsilon_{\mathrm{ii}}^{T} / \varepsilon_{0}-\right.$ $\varepsilon_{\mathrm{ii}}^{T_{0}} / \varepsilon_{0}, i=1,3$, and $T_{0}=150{ }^{\circ} \mathrm{C}$ ) as a function of temperature from $-150{ }^{\circ} \mathrm{C}$ to $150{ }^{\circ} \mathrm{C}$ were studied for LN crystals, as illustrated in Figure 2. The relative dielectric permittivities $\varepsilon_{11}^{T} / \varepsilon_{0}$ and $\varepsilon_{33}^{T} / \varepsilon_{0}$ were 83.2 and 29.4 at room temperature, respectively. The $\varepsilon_{11}^{T} / \varepsilon_{0}$ and $\varepsilon_{33}^{T} / \varepsilon_{0}$ were 78.0 and 26.3 at $-150{ }^{\circ} \mathrm{C}$, and then increased to 88.1 and 33.2 at $150{ }^{\circ} \mathrm{C}$, showing positive temperature variations. The dielectric losses for LN crystals along the $X$ - and $Z$-axes were lower, and the variations were smaller over the measured temperature range.

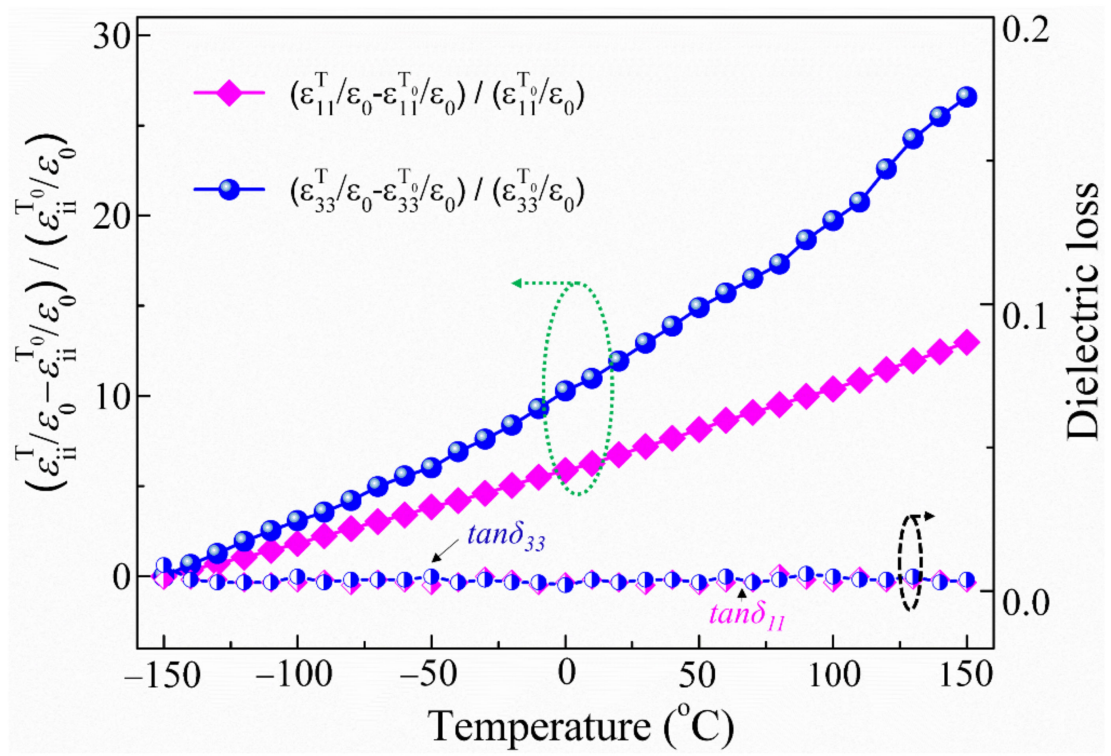

Figure 2. Variation of relative dielectric permittivity and dielectric loss for LN crystals. 


\subsection{Temperature Dependence of Elastic Compliance}

Based on the resonant and anti-resonant frequencies, the temperature dependent behaviors of elastic compliances were calculated. Figure 3 gave the elastic compliances of $\mathrm{LN}$ crystals as a function of temperature. The elastic compliance $s_{44}$ exhibited a large value, which was $16.0 \mathrm{pm}^{2} / \mathrm{N}$ at $-150{ }^{\circ} \mathrm{C}$, increasing to $16.9 \mathrm{pm}^{2} / \mathrm{N}$ at $150{ }^{\circ} \mathrm{C}$. The $s_{11}, s_{13}, s_{33}$ and $s_{44}$ all presented positive increases with increasing temperature, where the variations were $5.0 \%, 8.2 \%, 4.6 \%$ and $5.4 \%$, respectively, showing a good temperature stability.

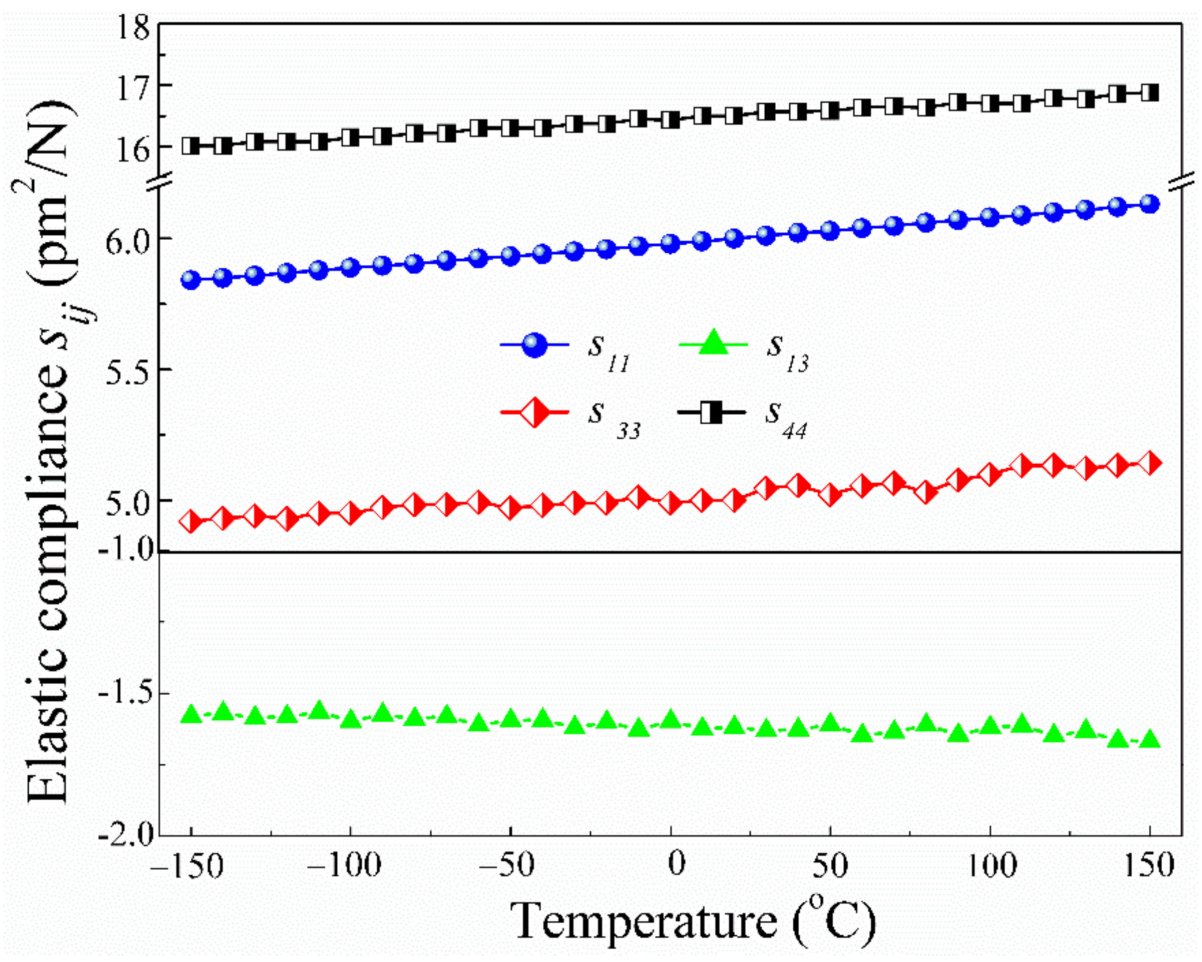

Figure 3. Variation of elastic compliance $s_{i j}$ for LN crystals.

\subsection{Temperature Dependence of Electromechanical Coupling Factor and Piezoelectric Coefficient}

The electromechanical coupling factors for different vibration modes, including the transverse length extensional mode, the longitudinal length extensional vibration mode and the thickness shear vibration mode of LN crystals, were investigated over a temperature range from $-150{ }^{\circ} \mathrm{C}$ to $150{ }^{\circ} \mathrm{C}$. The result was presented in Figure 4. It was observed that the LN crystals possessed high electromechanical coupling factors, $k_{15}$, measuring approximately $61.1-61.9 \%$ over the tested temperature range. The longitudinal length extensional vibration modes, $k_{22}$ and $k_{33}$, showed different trends: $k_{22}$ was determined to be $29.7 \%$ at $-150{ }^{\circ} \mathrm{C}$, then slightly declined to $29.4 \%$ at $150{ }^{\circ} \mathrm{C}$; while $k_{33}$ presented an increase from $22.1 \%$ to $23.4 \%$, with a variation of $5.6 \%$. The transverse length extensional mode $k_{31}$ was relatively small; approximately $2.5 \%$ at room temperature.

Combined with the determined dielectric constants, elastic compliances and electromechanical coupling factors, the variations in piezoelectric coefficients were obtained, as presented in Figure 5. The $d_{15}$ exhibited the largest piezoelectric response and a stable trend from $-150{ }^{\circ} \mathrm{C}$ to $150^{\circ} \mathrm{C}$; the variation was lower than $10 \%$. The larger piezoelectric coefficient was beneficial to enhance the sensitivity of the transducers. The $d_{22}, d_{33}$ and $d_{31}$ factors demonstrated growth as the temperature increased; the variations were $7.5 \%, 25.6 \%$ and $41.4 \%$, respectively. The larger variations of $d_{33}$ and $d_{31}$ were attributed to the larger increase in the relative dielectric permittivity $\varepsilon_{33}^{T} / \varepsilon_{0}$. Furthermore, the variation of the piezoelectric coefficient $d_{22}$ for LN and $\alpha$-BIBO crystals was investigated. The results were presented in the small inset of Figure 5. Compared with the $\alpha$-BIBO crystal, LN showed smaller variations in the same temperature range. The large piezoelectric coefficients and a 
good temperature stability were beneficial for the transducer applications of LN crystals at low temperatures.

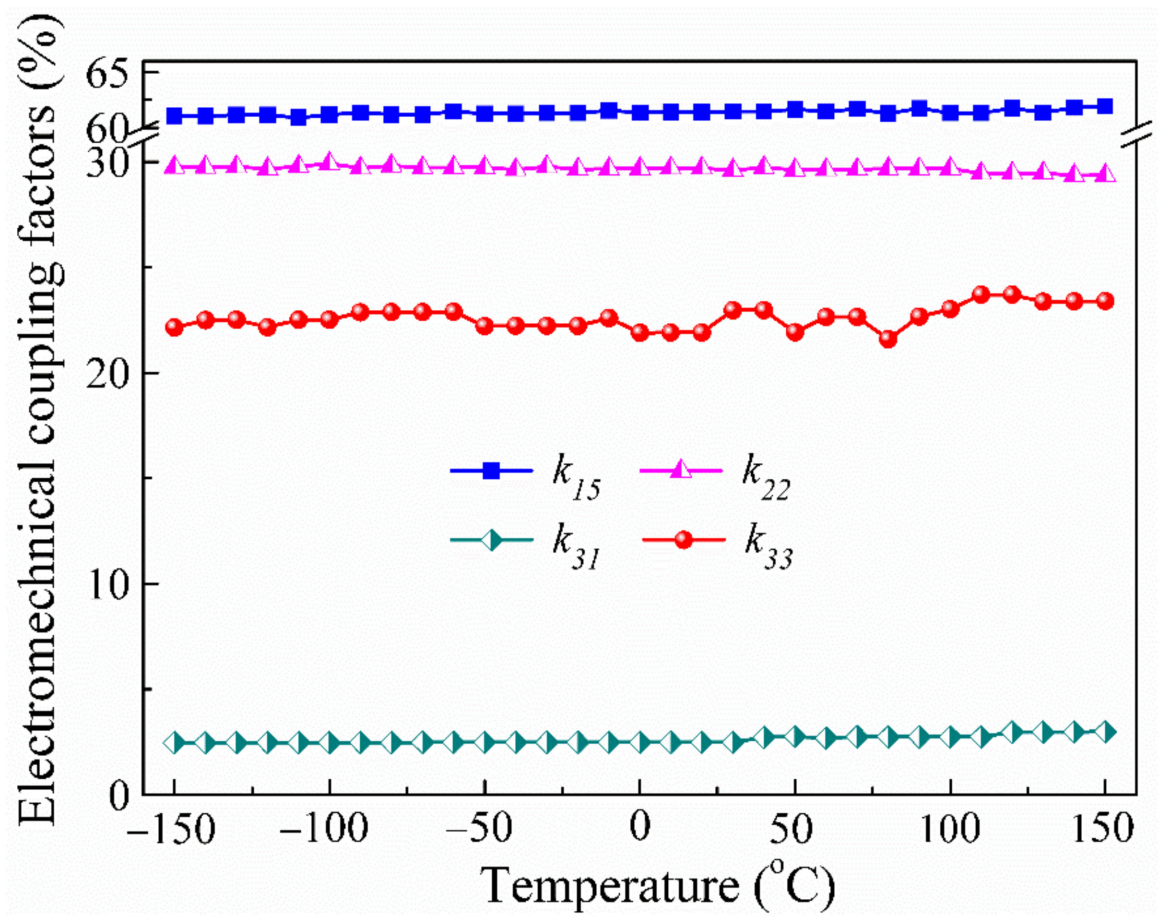

Figure 4. Variation of electromechanical coupling factor $k_{i j}$ for LN crystals.

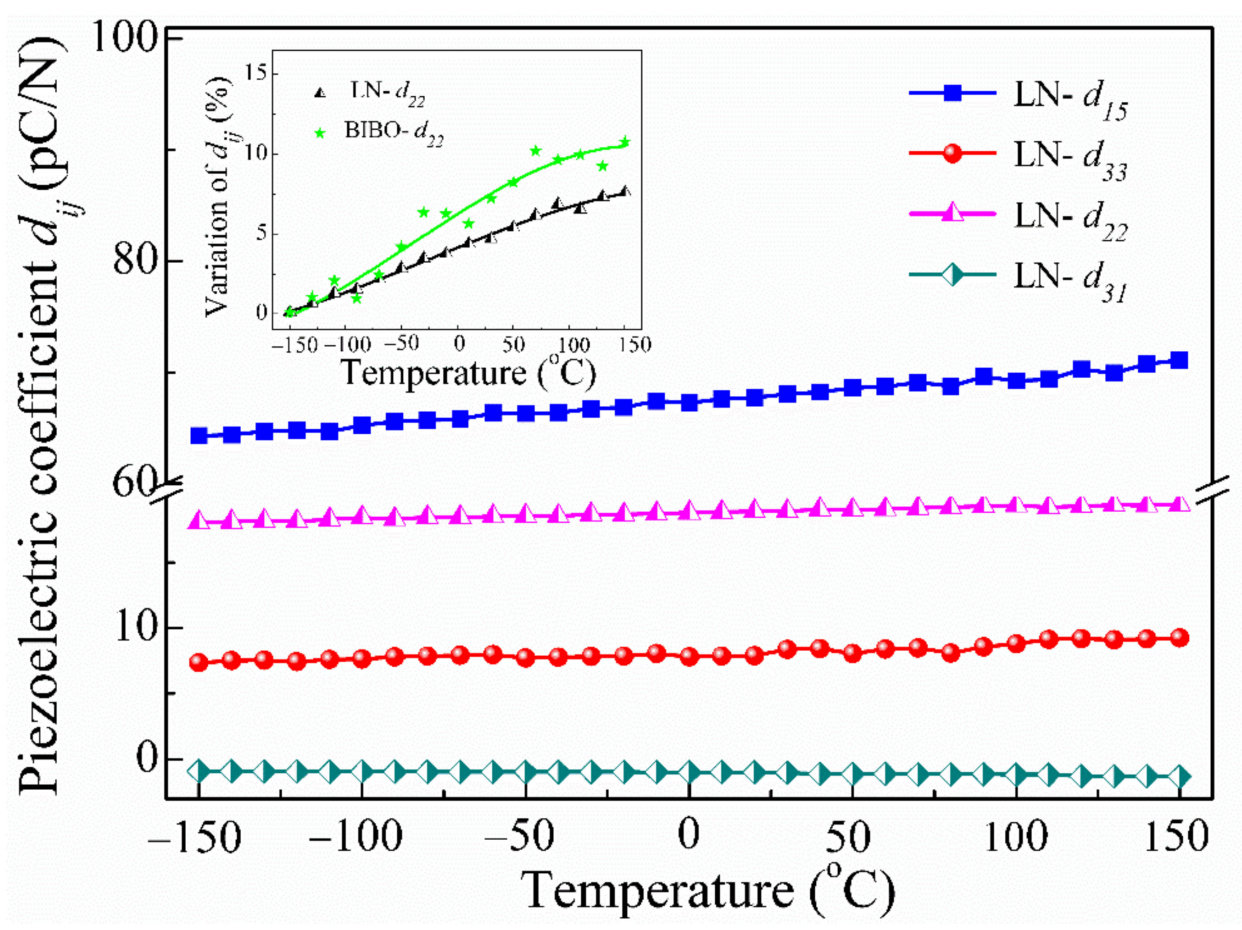

Figure 5. Variation of piezoelectric coefficient $d_{i j}$ for LN crystals.

\section{Conclusions}

In this work, the temperature stability of the electro-elastic properties for LN single crystals was investigated with a temperature range from $-150^{\circ} \mathrm{C}$ to $150^{\circ} \mathrm{C}$. The $\mathrm{LN}$ crystals were reported to possess large dielectric permittivities and low dielectric losses. The LN 
crystals presented a good temperature stability of elastic compliances. Moreover, the temperature dependence of electromechanical coupling factors and piezoelectric coefficients for LN crystals were studied, where the high coupling factor $k_{15}$ measured approximately $61.1-61.9 \%$ from $-150{ }^{\circ} \mathrm{C}$ to $150{ }^{\circ} \mathrm{C}$. The $d_{15}$ exhibited the largest piezoelectric response and a stable variation trend $(<10 \%)$, and the $d_{22}, d_{33}$ and $d_{31}$ showed an increase over the tested temperature range.

Author Contributions: Conceptualization, F.C. and F.Y.; methodology, C.J.; validation, F.C., C.J. and F.Y.; formal analysis, F.C.; investigation, F.C. and X.C.; resources, F.C. and F.Y.; writing-original draft preparation, F.C., C.J.; writing—review and editing, F.Y. and X.Z.; supervision, X.Z. All authors have read and agreed to the published version of the manuscript.

Funding: This work was supported by the National Natural Science Foundation of China (Grant No. 51872165), the Primary Research \& Development Plan of Shandong Province (Grant Number: 2019JZZY010313), Shandong Provincial Natural Science Foundation (Grant No. ZR2020KA003) and the Shandong Province Innovative Talents Support Program (No. 62350070311104).

Institutional Review Board Statement: Not applicable.

Informed Consent Statement: Not applicable.

Acknowledgments: This work received technical support from the Center for Optics Research and Engineering, State Key Laboratory of Crystal Materials in Shandong University.

Conflicts of Interest: The authors declare no conflict of interest.

\section{References}

1. Bartasyte, A.; Margueron, S.; Baron, T.; Oliveri, S.; Boulet, P. Toward high-quality epitaxial $\mathrm{LiNbO}_{3}$ and $\mathrm{LiTaO}_{3}$ thin films for acoustic and optical applications. Adv. Mater. Interfaces 2017, 4, 1600998. [CrossRef]

2. Sánchez-Dena, O.; Fierro-Ruiz, C.D.; Villalobos-Mendoza, S.D.; Flores, D.M.C.; Elizalde-Galindo, J.T.; Farías, R. Lithium niobate single crystals and powders reviewed-Part I. Crystals 2020, 10, 973. [CrossRef]

3. Sánchez-Dena, O.; Villalobos-Mendoza, S.D.; Farías, R.; Fierro-Ruiz, C.D. Lithium niobate single crystals and powders reviewedPart II. Crystals 2020, 10, 990. [CrossRef]

4. Liu, H.; Sang, Y.H.; Sun, D.H.; Wang, D.Z.; Wang, J.Y. Lithium niobate crystals in the information age: Progress and prospect. J. Synth. Cryst. 2021, 50, 708-715.

5. Sun, J.; Hao, Y.X.; Zhang, L.; Xu, J.J.; Zhu, S.N. Brief review of lithium niobate crystal and its applications. J. Synth. Cryst. 2020, 49, 947-964.

6. Zhang, F.; Kang, H.; Lin, Y.X.; Guan, L.; Aslan, H.; Zhang, M.N.; Niu, L.; Dong, M.D. Studying the pyroelectric effects of LiNbO 3 modified composites. Nanoscale Res. Lett. 2020, 15, 106. [CrossRef] [PubMed]

7. Kong, Y.F.; Bo, F.; Wang, W.W.; Zheng, D.H.; Liu, H.D.; Zhang, G.Q.; Rupp, R.; Xu, J.J. Recent progress in lithium niobate: Optical damage, defect simulation, and on-chip devices. Adv. Mater. 2020, 32, 1806452. [CrossRef] [PubMed]

8. Tian, S.W.; Jiang, C.; Chen, F.F.; Yu, F.P.; Li, Y.L.; Cheng, X.F.; Wang, Z.P.; Zhao, X. Damage mechanism and electro-elastic stability of $\mathrm{LiNbO}_{3}$ crystals irradiated with $6 \mathrm{MeV} \mathrm{Xe}^{23+}$. RSC Adv. 2020, 10, 21754-21759. [CrossRef]

9. Kadota, M.; Tanaka, S.J. Wideband acoustic wave resonators composed of hetero acoustic layer structure. Jpn. J. Appl. Phys. 2018, 57, 07LD12. [CrossRef]

10. Liu, C.; Yang, K.; Zhao, S.; Li, Y.; Li, G.; Li, D.; Li, T.; Qian, W.; Feng, T.; Chen, X. 88 ns multi-millijoule LiNbO3 electro-optically Q-switched Tm:LuAG laser. Opt. Commun. 2015, 355, 167-171. [CrossRef]

11. Guo, Y.J.; Zhang, J.; Zhao, C.; Hu, P.A.; Zu, X.T.; Fu, Y.Q. Graphene/ $\mathrm{LiNbO}_{3}$ surface acoustic wave device based relative humidity sensor. Optik 2014, 125, 5800-5802. [CrossRef]

12. Xu, Z.P.; Xu, S.W.; Xu, Y.H. Growth of In: Fe: $\mathrm{LiNbO}_{3}$ crystals and its application in holographic associative storage. J. Chin. Ceram. Soc. 2005, 33, 950-953.

13. Dagli, N. High-Speed Photonic Devices, Series in Optics and Optoelectronics; CRC Press: Boca Raton, FL, USA, 2006.

14. Osugi, Y.; Yoshino, T.; Suzuki, K.; Hirai, T. Single crystal FBAR with $\mathrm{LiNbO}_{3}$ and $\mathrm{LiTaO}_{3}$ piezoelectric substance layers. In Proceedings of the 2007 IEEE/MTT-S International Microwave Symposium, Honolulu, HI, USA, 3-8 June 2007; pp. 873-876.

15. Wang, Y.; Jiang, Y.J. Crystal orientation dependence of piezoelectric properties in $\mathrm{LiNbO}_{3}$ and $\mathrm{LiTaO}_{3}$. Opt. Mater. 2003, 23, 403-408.

16. Zhang, P.L.; Zhong, W.L. Piezoelectric Materials and Device Physics; Shandong Technology Press: Jinan, Chnia, 1997.

17. Weng, W.S. Electromechanical coupling coefficients for some modes of vibration of lithium niobate single crystal. Acta Acust. 1985, 10, 180-189. 
18. Pop, F.V.; Kochhar, A.S.; Vidal-Alvarez, G.; Piazza, G. Laterally vibrating lithium niobate mems resonators with $30 \%$ electromechanical coupling coefficient. In Proceedings of the 2017 IEEE 30th International Conference on Micro Electro Mechanical Systems (MEMS), Las Vegas, NV, USA, 22-26 January 2017; pp. 22-26.

19. Bai, X.Y.; Yao, S.; Luo, W.B.; Wu, C.G.; Zhang, W.L. The simulation of resonant mode and effective electromechanical coupling coefficient of lithium niobate crystal with different orientations. J. Phys. Conf. Ser. 2020, 1637, 012064. [CrossRef]

20. Smith, R.T.; Welsh, F.S. Temperature dependence of the elastic, piezoelectric, and dielectric constants of lithium tantalate and lithium niobate. J. Appl. Phys. 1971, 42, 2219-2230. [CrossRef]

21. Tarumi, R.; Matsuhisa, T.; Shibutani, Y.J. Low temperature elastic constants and piezoelectric coefficients of $\mathrm{LiNbO}_{3}$ and $\mathrm{LiTaO}_{3}$ : Resonant ultrasound spectroscopy measurement and lattice dynamics analysis. Jpn. J. Appl. Phys. 2012, 51, 07GA02. [CrossRef]

22. Chen, F.F.; Kong, L.F.; Song, W.; Jiang, C.; Tian, S.W.; Yu, F.P.; Qin, L.F.; Wang, C.M.; Zhao, X. The electromechanical features of $\mathrm{LiNbO}_{3}$ crystal for potential high temperature piezoelectric applications. J. Mater. 2019, 5, 73-80. [CrossRef] 